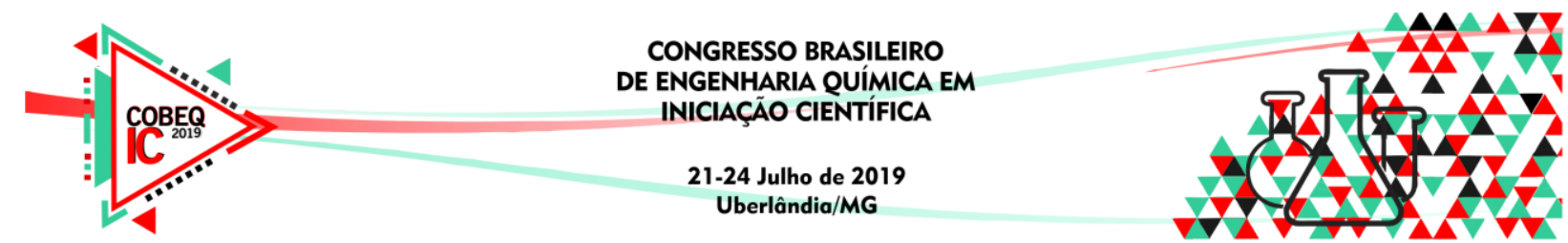

\title{
INFLUÊNCIA DA VAZÃO, VOLUME E AGITAÇÃO NA CONVERSÃO NO REATOR CSTR.
}

\author{
M.M. FILHO ${ }^{1}$, M.V.F. BASILIO ${ }^{1}$ e H.F. PINTO $^{1}$ \\ ${ }^{1}$ Centro Universitário da Fundação Educacional de Barretos, Departamento de Engenharia \\ Química \\ E-mail para contato: meneghettifilho@gmail.com
}

\begin{abstract}
RESUMO - O estudo das variáveis de processo são importantes para determinar e projetar o reator. Portanto entende-se que o controle dessas variáveis é de fundamental importância para que o objetivo final de produção seja estabelecido. Foi estudado a influência do volume, vazão e o nível de agitação em relação a conversão do reagente limitante. O experimento foi realizado em escala piloto, fazendo uso de um protótipo CSTR, variando a velocidade de rotação do impelidor em 30 e 60 rpm, com as demais variáveis constantes. Variou também as taxas de escoamento, entre 120, 200 e $220 \mathrm{~mL} \cdot \mathrm{min}^{-1}$, com as demais condições constantes e por fim o volume do reator entre 3,5 e $7 \mathrm{~L}$. A partir do cálculo da constante cinética, foi possível determinar a conversão do reator nas condições citadas, através de uma metodologia eficiente. Algumas das conclusões mostraram que a conversão se comportou conforme previsto pela literatura, a conversão experimental se comparado a conversão teórica foi satisfatória. Os níveis de vazões estabelecidas apresentam intrinsicamente relações especiais com o tempo de residência, que influência na conversão de matéria. Também foi analisado que a agitação do meio e a devida mistura da massa de fluido, contribui para a conversão, sendo que em níveis mais altos de agitação obtivera-se conversões relativamente maiores. $\mathrm{O}$ aumento do volume do reator também tem um efeito positivo na conversão. $\mathrm{O}$ parâmetro que mais influenciou na conversão foi o volume do reator.
\end{abstract}

\section{INTRODUÇÃO}

Os reatores são equipamentos especializados em realizar reações químicas, e estes, oferecem a possibilidade de poder controlar o processo, desde a quantidade desejada de reagentes que entra no processo, até a quantidade estabelecida de lotes produzidos. Desta maneira, Frost e Pearson (1952), afirma que do projeto ou da operação do reator químico dependerão os projetos e operações das demais unidades, que os precedem ou que os sucedem, assim estudar a reação química e o reator é de fundamental importância. Os reatores devem promover o contato íntimo entre os reagentes afim de que a reação de interesse ocorra, além disso fornece um ambiente apropriado em termos de pressão, temperatura, concentração de reagentes, agitação e presença de catalisador durante certo tempo que os reagentes se convertem em produtos. (Ranade, 2011). 


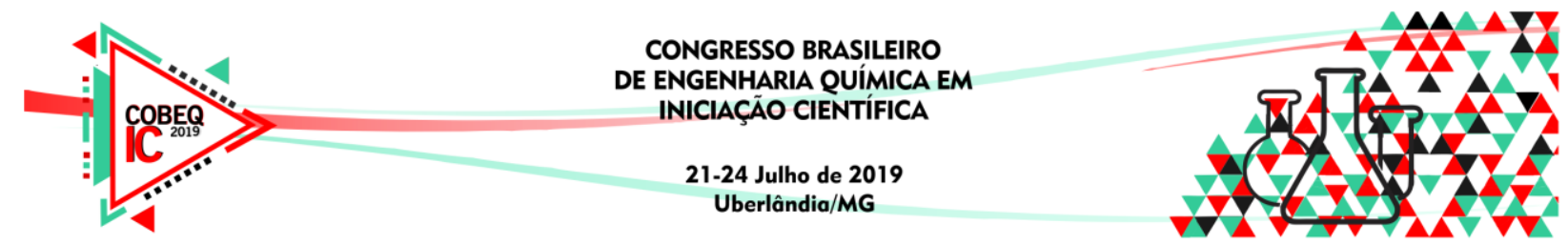

Perry e Green (2008) afirmam que, os reatores são equipamentos utilizados para garantir que as condições reacionais sejam atendidas. Reatores que operam de forma contínua, trabalham com uma ou várias entradas para injeção dos reagentes e com uma ou várias saídas para recolher o produto gerado. Reatores de tanque continuamente agitados, CSTR (Continuous Stirred Tank Reactor), são comumente encontrados em ambientes industriais de elevadas produções diárias. Mota e Vieira (2015), afirmam que são reatores que trabalham principalmente com reações em fase líquida, em regime estacionário.

$\mathrm{Na}$ indústria são muito utilizados quando o volume final que se deseja produzir seja muito elevado. A natureza deste sistema de reação resulta em baixos custos de operação, e, na maioria dos casos uniformidade do produto. (Nogueira, 2001). Seguindo a mesma linha de pensamento, Nogueira (2001), expõe um exemplo para processos de polimerização, neste utiliza-se reatores contínuos pois cada vez mais os polímeros são produzidos em grandes lotes.

Neste trabalho, através de uma reação de saponificação foram conduzidos testes em um reator em escala piloto utilizando acetato de etila e hidróxido de sódio afim de observar as alterações nas conversões finais do reagente limitante, quando são alteradas as vazões de entrada, os volumes dos reatores e os níveis de agitação dentro do tanque. Os resultados finais foram comparados a literatura para a validação final.

\section{MATERIAIS E MÉTODOS}

\subsection{Materiais}

Para a construção do reator utilizou dois galões de água de 20 litros para os reservatórios, tubulações PVC de 3/4 polegadas para o transporte de reagentes do reservatório ao reator. $\mathrm{O}$ controle da vazão foi feito através de válvulas do tipo esfera. O reator CSTR foi construído com um vaso de PVC de aproximadamente 10 polegadas. Motor de redução de 12 Volts e uma pá de ferro foram responsáveis pela agitação no interior do vaso, necessitou-se também de uma fonte regulada (FR-25-50) para o fornecimento da energia ao motor. Um suporte de ferro e vidrarias de laboratório como béquer, bureta, erlenmeyer e balão volumétrico, além de balança analítica e agitador magnético (Fisatom 752A). Os materiais químicos usados para a reação neste trabalho foram hidróxido de sódio $\mathrm{PA}(\mathrm{NaOH})$ e acetato de etila PA $\left(\mathrm{CH}_{3} \mathrm{COOC}_{2} \mathrm{H}_{5}\right)$, além de ácido clorídrico $(\mathrm{HCl})$ e fenolftaleína $\left(\mathrm{C}_{2} \mathrm{OH}_{14} \mathrm{O}_{4}\right)$ utilizados na titulação. Cerca de 160 litros de água destilada $\left(\mathrm{H}_{2} \mathrm{O}\right)$ para o preparo das soluções, para a armazenagem dessas soluções utilizou galões de plástico. Cronômetros e proveta foram usados na determinação das vazões.

\subsection{Montagem do reator}

Na parte inferior de cada galão de água foi feita uma abertura e fixado um cano de PVC de 3/4 polegadas. Em cada tubulação acoplou-se uma válvula do tipo esfera. Na tampa do reator foi realizado 3 aberturas, duas para a entrada dos reagentes e uma para inserir um motor de redução de 12 Volts, ao motor foi encaixado a pá de ferro, além de ser conectado a fonte regulada (FR-25-50). Na saída do vaso foi acoplado mais uma válvula de esfera, após a esta válvula foi colocado um recipiente de 25 litros. Todo esse sistema foi instalado em um suporte de ferro como ilustrado na figura 1. 


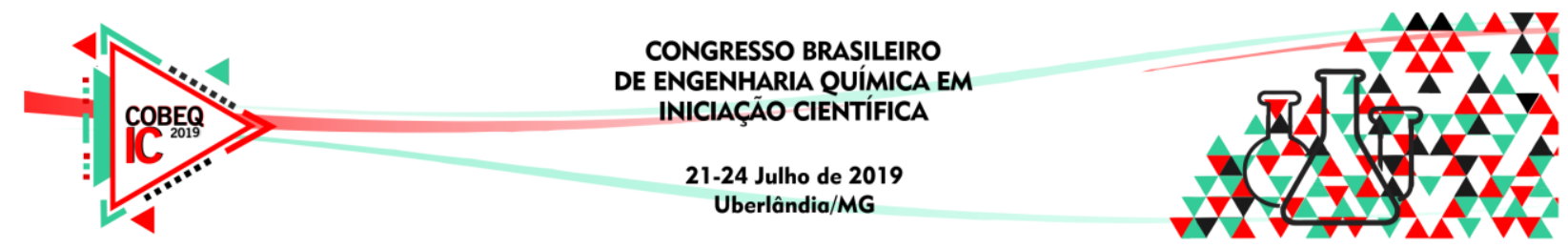

Figura 1: Sistema do reator CSTR já finalizado.

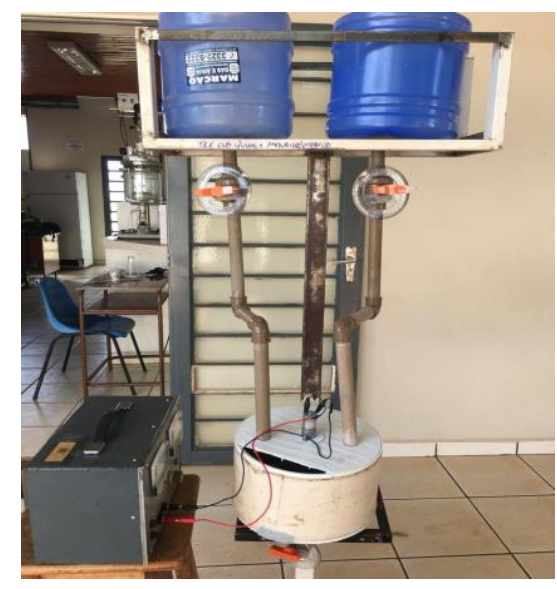

\subsection{Operação do reator}

Inicialmente foram completados manualmente cada um dos reservatórios com as soluções de Hidróxido de Sódio e Acetato de etila preparadas a 0,1 mol.L $\mathrm{L}^{-1}$ e temperatura ambiente $\left(25^{\circ} \mathrm{C}\right)$. Antes de direcionar os reagentes para o interior do reator, acertou a vazão desejada utilizando um cronômetro e proveta, esse procedimento foi executado num béquer fora do vaso. Após completou o reator com 50\% de seu volume para ambas as soluções, em seguida imediatamente transferiu as tubulações das soluções para o interior do reator, ligou-se a agitação e abriu a válvula de saída do mesmo. Essa abertura da válvula de saída foi estabelecida de maneira que o volume no interior do vaso fosse mantido constante. Após o início do sistema, esperou-se 40 minutos para que operasse em regime permanente, passado esse tempo, alíquotas de $10 \mathrm{~mL}$ foram retiradas na saída do CSTR em intervalos de tempo e transferidas para erlenmeyer contendo ácido clorídrico e levadas para titulação. Os níveis dos reservatórios foram mantidos sempre cheios durante o procedimento para que não houvesse oscilação da vazão, já que o sistema operou por gravidade. Este procedimento foi realizado 6 vezes, variando as vazões entre 100,200 e $220 \mathrm{~mL} \cdot \mathrm{min}^{-1}$, o volume do reator em 3,5 e $7 \mathrm{~L}$, e rotação do agitador a 30 e 60rpm. Os testes foram realizados em triplicata e o erro experimental entre cada teste foi muito baixo (desprezível). Os resultados foram analisados a partir das interferências destas variáveis na conversão no CSTR.

Desta maneira, foi possível avaliar o rendimento do processo de saponificação e estabelecer uma relação entre conversão teórica e experimental. Ou seja, o que poderia ser convertido em condições ideais de processo e o que realmente foi convertido durante a experimentação. Para o cálculo da conversão teórica seguiu um modelo proposto por Fogler (2012) onde $\mathrm{Vr}$ representa o volume do reator, $\mathrm{C}_{\mathrm{A} 0}$ a concentração inicial da espécie $\mathrm{A}, \mathrm{C}_{\mathrm{B} 0}$ para concentração inicial da espécie $B, \dot{V}_{0}$ vazão volumétrica inicial, $X_{A}$ para a conversão em relação a espécie A e K a constante de velocidade da reação, conforme a equação 1.

$$
V r=\frac{C_{A 0} \dot{V}_{0} X_{A}}{K C_{A 0}\left(1-X_{A}\right)\left(C_{B 0}-C_{A 0} X_{A}\right)}
$$

Conforme descrito na equação 2 , o cálculo da conversão experimental percentual, $\mathrm{X}_{\mathrm{A}}$, pode ser representada em termos de concentração dos reagentes iniciais, $C_{A 0}$ e finais, $C_{A}$. 


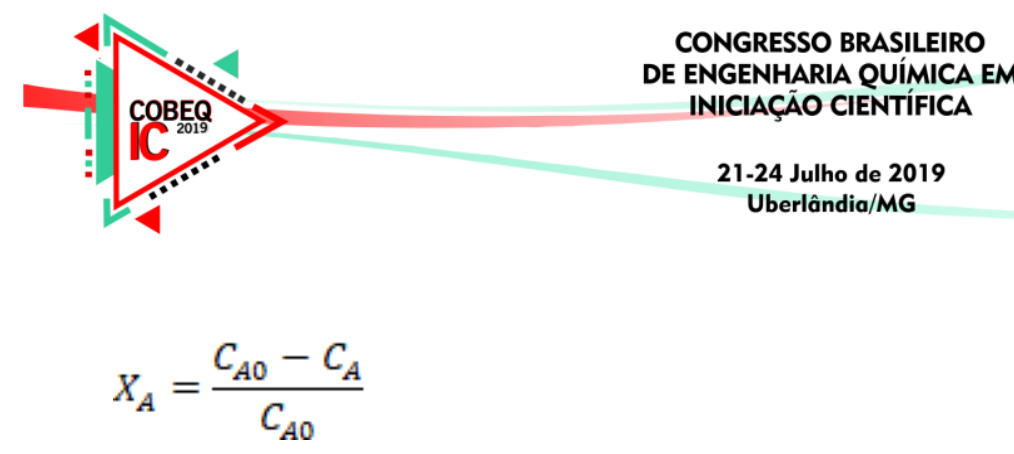

\section{RESULTADOS E DISCUSSÕES}

\subsection{Experimento A: Efeito da agitação sobre a conversão}

Para análise da influência da velocidade de rotação do agitador sobre a conversão no reator, fixou-se as vazões de entrada dos reagentes em $120 \mathrm{~mL} \cdot \mathrm{min}^{-1}$, o volume do reator em 5 litros, com concentrações iniciais equivalentes a 0,1 mol. $\mathrm{L}^{-1}$ e temperatura ambiente de aproximadamente $25^{\circ} \mathrm{C}$, sabendo-se também que o valor da constante cinética é $\mathrm{K}=0,2195$ L.mol ${ }^{-1} . \mathrm{s}^{-1}$, variando somente a rotação do agitador em 30 e $60 \mathrm{rpm}$. A figura 2 compara os valores obtidos para a conversão teórica e experimental influenciadas pela velocidade do misturador.

Figura 2: Variação da conversão a partir da variação da velocidade do agitador.

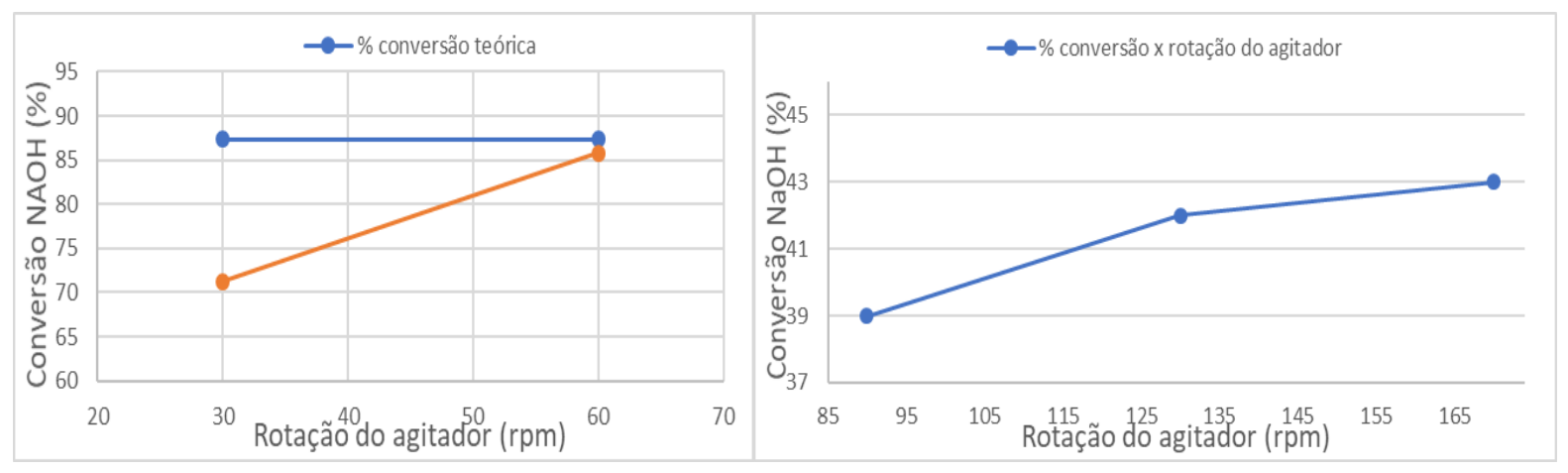

Figura 2: Dos autores

Figura 3: Adaptado de DANISH; MESFER; RASHID, 2015

Observa-se, a partir do gráfico que a conversão experimental de hidróxido de sódio é proporcional a velocidade de rotação do agitador, ou seja, quanto maior a agitação, maior a conversão do reator, devido as moléculas reagentes serem influenciadas pela pá do agitador, e quanto maior a agitação maior é a colisão das espécies. É possível verificar também que os valores da conversão teórica se mantiveram constantes. Isso se dá ao fato de, na fórmula da conversão teórica não haver nenhum fator relacionado a agitação. Ou seja, para qualquer velocidade de agitação a conversão permaneceria a mesma. O valor do desvio deu relativamente alto pelo fato de a conversão experimental relacionada a rotação de $30 \mathrm{rpm}$ ser baixa, afastando da idealidade. No estudo conduzido por Danish, Mesfer e Rashid (2015), foram utilizados acetato de etila e hidróxido de sódio. A concentração de ambas as soluções foi $0,1 \mathrm{M}$. O reator utilizado foi o CSTR e o estado estacionário demorou 30 minutos para ser atingido.

\subsection{Experimento B: Efeito do volume do reator sobre a conversão}

Para determinação da influência do volume do reator sobre a conversão, trabalhou-se com concentrações iniciais dos reagentes equivalentes a 0,1 mol. $\mathrm{L}^{-1}$, a temperatura ambiente. 

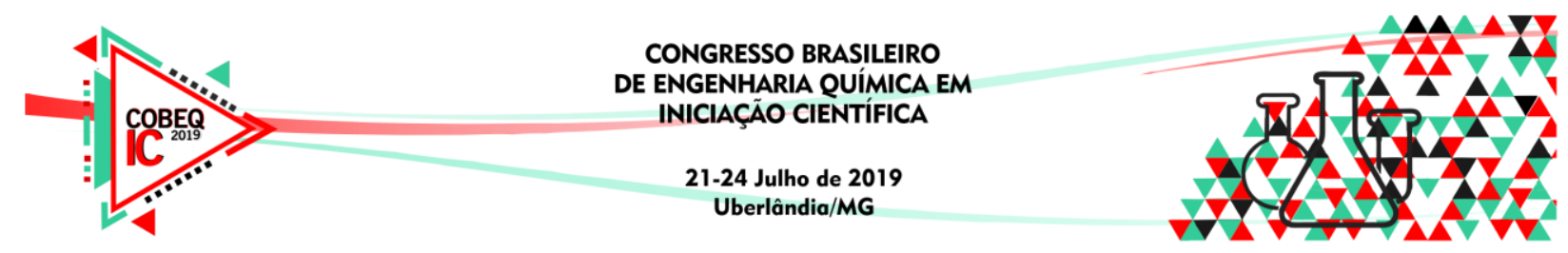

Optamos por utilizar uma vazão de $200 \mathrm{~mL} \cdot \mathrm{min}^{-1}$ para facilitar nos cálculos e velocidade de agitação correspondente a $60 \mathrm{rpm}$, o valor da constante cinética $\mathrm{K}=0,2195 \mathrm{~L} \cdot \mathrm{mol}^{-1} \cdot \mathrm{s}^{-1}$. Variando somente o volume do reator em 3, 5 e 7 litros. A figura 4 compara os valores obtidos para a conversão teórica e experimental influenciadas pelo volume do reator.

Figura 4: Variação da conversão a partir da variação do volume do reator.

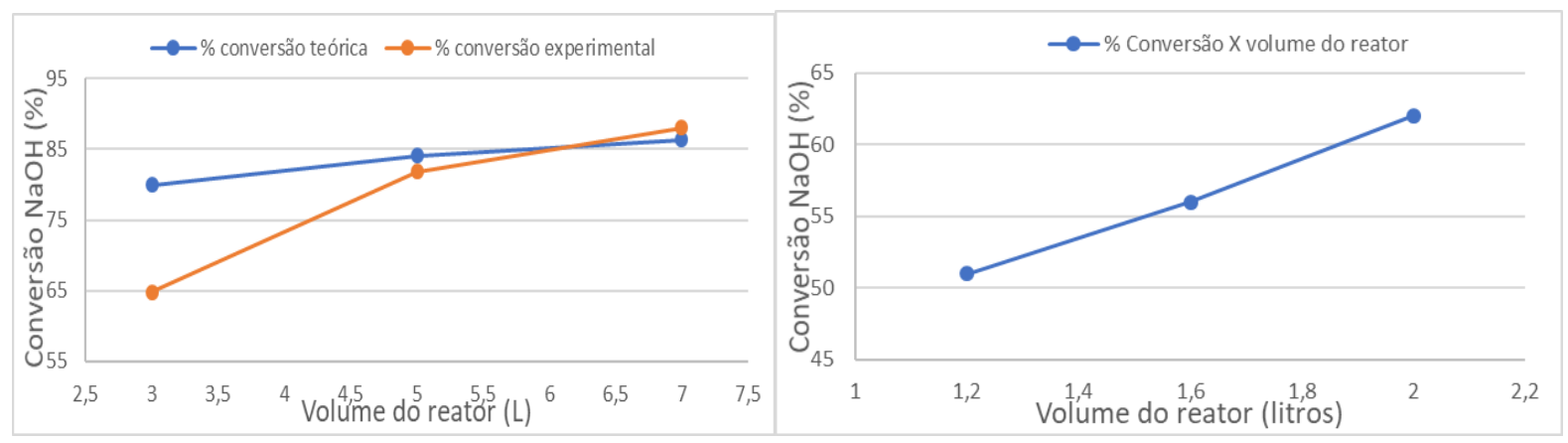

Figura 4: Dos autores

Figura 5: Adaptado de DANISH; MESFER; RASHID, 2015

A partir da inclinação das retas, é observado ao iniciar com um volume menor a conversão experimental também é menor, já com um maior volume do meio reacional, maior será a conversão obtida. Isso acontece devido ao aumento no tempo de residência das moléculas no interior do reator, ou seja, quanto maior o volume reacional maior será o tempo de interação entre as moléculas reagentes.

\subsection{Experimento C: Efeito da vazão sobre a conversão}

Para verificar o efeito da vazão sobre a conversão do reator, realizou-se o experimento a temperatura ambiente de aproximadamente $25^{\circ} \mathrm{C}$, concentrações iniciais dos reagentes iguais a $0,1 \mathrm{~mol} . \mathrm{L}^{-1}$, com velocidade de agitação equivalente a $60 \mathrm{rpm}$ e por escolha com o volume do reator de 5 litros, e sabendo que a constante de velocidade $\mathrm{K}=0,2195 \mathrm{~L} \cdot \mathrm{mol}^{-1} \cdot \mathrm{s}^{-1}$. Variouse somente as vazões de entrada dos reagentes em 120, 200 e $220 \mathrm{~mL} \cdot \mathrm{min}^{-1}$. A figura 6 compara os valores obtidos para a conversão teórica e experimental influenciadas pelo fluxo de reagentes.

Figura 6: Variação da conversão a partir da variação da vazão de entrada dos reagentes.
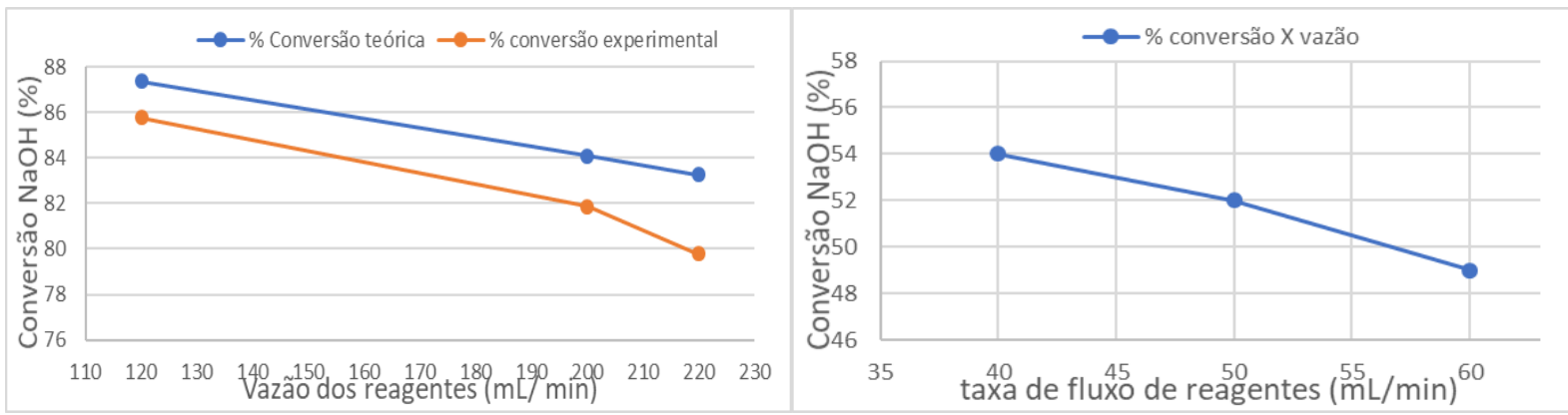

Figura 6: Dos autores.

Figura 7: Adaptado de DANISH; MESFER; RASHID, 2015 


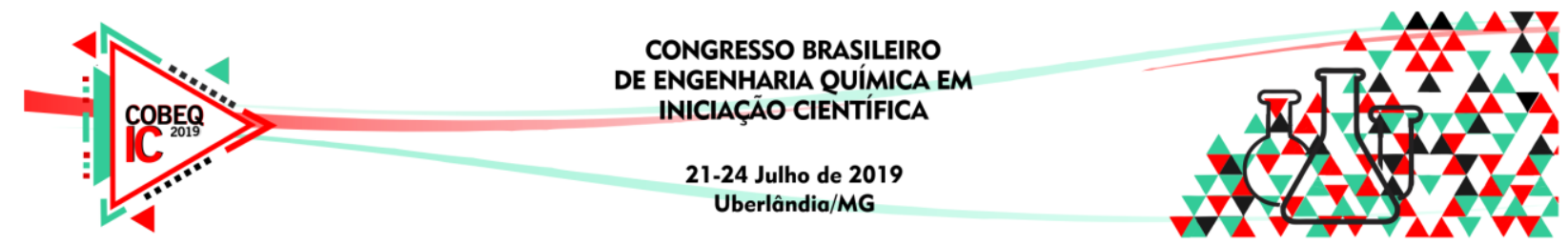

A figura 6 mostra que, tratando-se de vazão de entrada dos reagentes, a conversão se comporta de forma contrária as outras variáveis, ou seja, a medida que a vazão aumenta, a conversão de $\mathrm{NaOH}$ diminui em consequência a diminuição no tempo de residência das moléculas e no tempo de reação das substancias reagentes. Pode-se observar que a conversão real do experimento foi próxima da ideal (teórica). Essa pequena variação explica-se pelo fato de ocorrer erros experimentais, tais como instrumentos de leitura, uma pequena variação na vazão dos reagentes, zonas estagnadas, entre outros.

\section{CONCLUSÃO}

A agitação é um fator importante quando deseja-se obter uma mistura eficiente e conversão maior. Nota-se um visível aumento na conversão conforme o número de rotações por minuto (rpm) do agitador vai aumentando. Pode-se determinar que a conversão da reação diminuiu com o aumento na taxa de fluxo dos reagentes. $\mathrm{O}$ aumento do volume do reator também tem efeito positivo na conversão. A influência de condições operacionais obtidas neste trabalho como taxa de fluxo de reagentes, taxa de agitação e volume do reator na conversão comportou-se como mencionado pela literatura, aumentando ou diminuindo conforme a variação de certos parâmetros. Pode-se concluir também que os desvios da conversão experimental em relação a teórica deram valores relativamente baixos comprovando que a metodologia utilizada neste trabalho foi eficiente.

\section{REFERÊNCIAS}

FOGLER, H. S. Elementos de Engenharia das Reações Químicas, $4^{\mathrm{a}}$ ed. Editora LTC. São Paulo: 2012.

FROST, A. A.; PEARSON, G. R. Kinetics and Mechanism: A Study of homogeneous Chemical Reactions, $1^{\mathrm{a}}$ ed. Editora Wiley. Nova Iorque: 1952.

MOTA, M. V. de C.; VIEIRA, F. T.; "Análise do reator do tipo tanque agitado (CSTR): comportamento dinâmico na partida e estabilidade da operação estacionária. São Paulo: Blucher, 2015.

NOGUEIRA, André Lourenço. Modelagem matemática e simulação numérica de um sistema reacional composto por reatores tipo tanque agitado e tubular em processos de polimerização I. Campinas, SP: [s.n.], 2001.

PERRY, R. H.; GREEN, D. W. Perry's Chemical Engineers' Handbook. 8. ed. Nova Iorque: McGraw-Hill, 2008.

RANADE, V. V. Computational flow modeling for chemical reactor engineering. London, England: Academic press, 2001. 